\title{
Number and Severity of Type 2 Diabetes among Family Members Are Associated with Nutrition and Physical Activity Behaviors
}

\author{
Ann Oyare Amuta ${ }^{1 *}$, Rahma Mkuu ${ }^{2}$, Wura Jacobs ${ }^{3}$ and Adam E. Barry ${ }^{2}$ \\ ${ }^{1}$ Health Studies, Texas Woman's University, Denton, TX, United States, ${ }^{2}$ Health \& Kinesiology, Texas A\&M University, College \\ Station, TX, United States, ${ }^{3} \mathrm{Health}$ Science, California State University Fullerton, Fullerton, CA, United States
}

OPEN ACCESS

Edited by:

Mohamed Abu-Farha,

Dasman Diabetes

Institute, Kuwait

Reviewed by:

Julie Anne Quinlivan,

Professional Services Review,

Australia

Amber B. Courville,

National Institutes of Health

Clinical Center,

United States

*Correspondence:

Ann Oyare Amuta

aamuta@twu.edu

Specialty section:

This article was submitted to

Diabetes,

a section of the journal

Frontiers in Public Health

Received: 31 January 2017

Accepted: 19 June 2017

Published: 13 July 2017

Citation:

Amuta $A O$, Mkuu R, Jacobs $W$ and Barry AE (2017) Number and Severity

of Type 2 Diabetes among Family

Members Are Associated

with Nutrition and Physical

Activity Behaviors.

Front. Public Health 5:157.

doi: 10.3389/fpubh.2017.00157
Aim: A binary measurement of type 2 diabetes (T2D) has been found not to influence behaviors. We aimed to examine the influence of other measures of family history such as number of relatives, genetic closeness of relatives, and severity of T2D of family members on nutrition and physical activity behaviors among college students.

Methods: Students across four colleges in Texas were sampled. Multiple linear regression models, controlling for covariates, were used to model results. Cross-sectional data were used.

Results: More number of relatives with T2D was associated with vegetable consumption $(\beta=0.131, p=0.007$ ) and exercise $(\beta=0.129, p=0.037)$. Having relatives with severe T2D was associated with vegetable consumption $(\beta=0.157, p=0.002)$ and exercise $(\beta=106, p=0.027)$. Closer genetic relationship with someone with T2D was associated with increased vegetable consumption ( $\beta=0.107, p=0.023)$ and exercise $(\beta=0.096, p=0.047)$.

Conclusion: It is likely that the severe complications that may accompany the relatives T2D or having an immediate family member living with T2D may in fact motivate other family members without T2D to modify their attitudes, beliefs, and knowledge about T2D, thus encourage health-protective behaviors.

Keywords: family history, type 2 diabetes, health promotion, diet, physical activity

\section{INTRODUCTION}

Type 2 diabetes (T2D) has been labeled an "adult onset" disease (1,2); yet, cases of T2D continue to escalate among children and adolescents $(3,4)$. By year 2050, the number of adolescents with T2D will increase to approximately 84,131 (4). The growing incidence of T2D among adolescents is closely tied to the rising prevalence of obesity (5). While there are several factors that influence obesity, and subsequently contribute to T2D, lifestyle-related behaviors are chief indicators.

Physical activity (PA) and dietary behavior have been highlighted as particularly effective T2D protective factors. PA is associated with lower rates of T2D (6-9). Specifically, moderate intensity PA, such as brisk walking, significantly reduces risk of T2D (10). Among college students, aerobic PA has led to decreased risk for T2D (11). Similarly, a healthy diet significantly reduces the risk of developing T2D. For instance, nutrients and phytochemicals present in vegetables are thought to protect against 
the occurrence of T2D $(12,13)$. Leafy greens, in particular, result in improved glucose metabolism (14) and ultimately decrease risk of developing T2D $(13,15)$. Those who develop T2D often fail to consume five or more fruits and vegetables per day, compared to those who did not have T2D (16).

Although diet and PA play an important role in preventing the development of T2D, it is a disease involving an intricate interaction between modifiable (e.g., diet and PA) and non-modifiable risk factors (e.g., genes and family history) (17). Non-modifiable factors, such as genetics, are noteworthy given that "children and full siblings may share up to $50 \%$ of their genes, grandparents may share up to $25 \%$ of genes, and maternal or paternal cousins share $15 \%$ of genes" $(18,19)$. Two genes in particular, calpain 10 and hepatocyte nuclear factor 4 alpha, have been identified as genes related to T2D (19). While genetic testing may not be attainable for all populations, it is noteworthy that family history might provide the necessary insights into specific conditions that "run in the family." In addition to genetics, parents and other family members influence the development of beliefs, attitudes, and behaviors, all of which influence dietary and activity behaviors (20-22). Furthermore, family members and relatives share an environment, such as living space and physical neighborhood, which further influence T2D susceptibility (17).

Type 2 diabetes family history health education interventions have positive effects on lifestyle behaviors among adults. For example, people who know that a family member has been diagnosed with T2D are more likely to lose weight, increase PA, and practice healthy eating (23-26) as well as engage in healthier lifestyle behaviors than those who are not knowledgeable about their family history of T2D (27). That said, among college-aged adolescents, the influence of family history does not mirror the general population. Studies on normal weight and obese/ overweight college students found no influence of family history status on health-protective behaviors (28-30). Some contend family history may not be as impactful among college students since they often underestimate their susceptibility to diseases (31) and do not understand the implications of family health history on an individual's health outcomes (32). While differences noted between the general population and college students may be due to inherent differences in life stage, it is possible that the manner T2D family history has been conceptualized or operationalized is the reason for these contrasting findings. For instance, most studies have used a binary format (i.e., yes/no) to measure knowledge of T2D family history status. By employing a binary format, variability is reduced and ultimately understanding of how family history impacts T2D-related behaviors is limited. For instance, some of the intricacies that would not be captured with a binary approach include: (a) having a family member with severe T2D (i.e., lower extremity amputations), (b) how close of a genetic relationship exists between family members (i.e., first, second, or third degree relatives), and (c) the number of people in an adolescent's family diagnosed with T2D (i.e., one person or eight people). Consequently, we sought to: (a) determine whether a binary measurement of T2D family history would exhibit a relationship to PA or nutritional behaviors among those with a positive T2D family history; (b) assess whether respondents with a family member experiencing severe T2D would engage in more frequent PA and consume greater quantities of vegetables than respondents without a family member with severe T2D; (c) quantify whether having more relatives with T2D would be associated with more frequent PA and consumption of more vegetables; and (d) whether having a closer genetic relationship with a T2D living relative would be associated with more frequent PA and consumption of greater quantities of vegetables than those who have a farther genetic relationship with a relative living with T2D.

\section{MATERIALS AND METHODS}

\section{Sample Selection and Participants}

Sample consisted of undergraduate students ( 18 or older) enrolled in four colleges/universities across a southern state. Institutional size ranged from 18,413 to 58,577 students. Solicitations were sent to student's school emails via administrative academic advisors. A total of 7,600 students were contacted across the four institutions, 905 of which responded (12\% response rate). All study procedures were vetted by the Institutional Review Boards for each respective institution. $\$ 40$ major-retailer gift card incentives were given to 13 participants via random drawing.

\section{Survey Instrument}

Family history was assessed via the item: "Have any of your family members (mother, father, brother, sister, grandparents on both mothers and fathers side, aunts and uncles on both mothers and fathers side, and cousins on both mothers and fathers side) ever been diagnosed with T2D?" Possible responses were "No," "Yes," "I don't know" and "Not applicable." The first level of analysis replicated prior literature by utilizing the binary level of T2D family history measurement (yes/no) on health behaviors; thus, responses were coded to create a dichotomous outcome variable for knowledge of T2D family history status, such that "Yes" (coded 1) indicated a positive family history while "No," "I don't know," and "Not applicable" (coded 0 ) indicated no family history of T2D. The second level of analyses included only respondents who had a family history of T2D and then stratified the risk by number of relatives with $\mathrm{T} 2 \mathrm{D}$, closeness of relationship with a relative with $\mathrm{T} 2 \mathrm{D}$, and severity of relatives with $\mathrm{T} 2 \mathrm{D}$.

\section{Degree of Relationship with Family Members with T2D}

Participants were asked to "select all that apply" to the following question: "which of the following relatives currently has T2D: mother, father, brother or sister, any grandparents on mothers side, any grandparents on fathers side, aunts or uncles on mothers side, aunts or uncles on fathers side, any cousins on mothers side, any cousins on fathers side." Responses were coded to create a dichotomous outcome variable per the degree of relationship with relative with T2D. Those who reported to have a first or second degree relative living with T2D was (coded 1), while those who indicated they had only third degree relatives with T2D were (coded 0 ). We coded the relationship this way because one of the hypotheses that guide this paper is that having a closer genetic and most likely social/cultural/environmental relationship with 
a relative with $\mathrm{T} 2 \mathrm{D}$ will heighten motivation to engage in $\mathrm{T} 2 \mathrm{D}-$ related protective behaviors.

\section{Number of Family Members with T2D}

Participants were asked to write down the number of living family members with T2D.

\section{Severity of Family Members' T2D}

Respondents were asked to "Please select if your family member or members with T2D has experienced or is experiencing any of the following: kidney disease, heart disease, blindness, limb amputation, or an emergency room visit for a T2D-related issue." Possible responses were "No," "Yes," and "I don't know." Responses were coded to create a dichotomous outcome variable for T2D relative severity status, such that "Yes" (coded 1) indicated that their family member had severe T2D "No," and "I don't know" (coded 0) indicated that their family member did not have severe T2D.

\section{Demographics}

Based on the Centers for Disease Control recommendations (33), body mass index (BMI, kilograms per square meter) was calculated on self-reported weight and height. Overweight was defined as BMI 25.0-29.9, and obesity as BMI $\geq 30.0$ (33). Other participants demographics included age (i.e., continuous variable ranging from age 18 to 27 years), biological sex (male coded 0 and female coded 1), and race/ethnicity (i.e., non-Hispanic white, African-American or black, Hispanic or Hispanic/Latino). These variables were included because there is evidence that they have associations with risk perception and health-protecting behaviors (34-37).

\section{Vegetable Consumption}

Vegetable consumption behaviors were measured by asking participants: "about how many cups of vegetables (including $100 \%$ pure vegetable juice) do you eat or drink each day? (1 cup of vegetables could be equal to: 3 broccoli spears, 1 cup cooked leafy greens, 2 cups lettuce or raw greens, 12 baby carrots, 1 medium potato, 1 large sweet potato, 1 large ear of corn, 1 large raw tomato, 2 large celery sticks, 1 cup of cooked beans)." Possible responses for this question were "Never" (coded as 0 ), " $1 / 2$ cup or less" (coded as 1), " $1 / 2$ cup to 1 cup" (coded as 2 ), " $1-2$ cups" (coded as 3 ), "2-3 cups" (coded as 4 ), “3-4 cups" (coded as 5), and " 4 or more cups" (coded as 6). This question was adapted from the Health Information National Trends Survey (38).

\section{PA Behavior}

Physical activity was assessed via two items: "during the last 7 days, on how many days did you do moderate physical activities like carrying light loads, bicycling at a regular pace, or doubles tennis? Do not include walking." 0 days (coded as 0 ), 1 day (coded as 1), 2 days (coded as 2), 3 days (coded as 3), 4 days (coded as 4), 5 days (coded as 5), 6 days (coded as 6), and 7 days (coded as 7 ); and "how much time in total did you usually spend on one of those days doing moderate physical activities?" Possible responses were open ended and participants were prompted to write the length of time in a box provided. All responses were in minutes. Responses to each of these items were multiplied to create a single, composite indicator of PA. For instance, if a respondent indicated they were at least moderately active 3 days a week, and they typically engaged in such activity for $40 \mathrm{~min}$, then their weekly PA would be $120 \mathrm{~min}$. "Higher scores indicated higher levels of PA each week." This question was adapted from the Health Information National Trends Survey (38).

\section{Statistical Analysis}

Means and SDs for continuous variables and frequencies for binary and categorical variables were calculated. Multiple linear regression was conducted to examine the impact of T2D familial risk profiles on related protective behaviors. Variables that have been established by the scientific literature as influencing health behaviors, such as age, sex, and race/ethnicity were controlled for (39-45). To analyze the binary measure of T2D family history, we used all the participants $(n=905)$; however, all other analyses of T2D family history, such as the number and type of relative with T2D, required that we extract only those with a T2D family history for the analyses $(n=441)$.

\section{RESULTS}

\section{Binary Measure of Family History and Health Behaviors}

The sample was primarily female $(81.5 \% ; n=736)$, White $(58.6 \%$; $528)$, and the average age was $21(\mathrm{SD}=1)$. Almost half $(48.8 \%$; $n=441$ ) had a family history of T2D. Majority of the sample consumed less than two cups of vegetables $(86 \% ; n=777$ ) (see Table 1). Based on the binary measurement of family history (yes/no) having a family history of T2D did not influence vegetable consumption $(B=0.135, \beta=0.085, p=0.115)$ or PA behaviors $(B=-4.811, \beta=-0.004, p=0.903)$ after controlling for demographic variables (see Table 2).

\section{A More Nuanced Approach to Measuring Family History and Health Behaviors}

Of the total number of participants $(n=905)$, approximately 441 reported a family member with $\mathrm{T} 2 \mathrm{D}$. The sample was primarily female $(85.5 \% ; n=375)$. Most respondents were white $(60 \% ; n=265)$. The average age of participants was 20 years old $(\mathrm{SD}=1)$. About half of the participants had a family member with severe T2D $(47.2 \% ; n=207)$, and majority had a first or

\begin{tabular}{llc} 
TABLE 1 | Demographic characteristics of all college students $(n=905)$. \\
\hline Sex & Male & $163(18.1 \%)$ \\
& Female & $736(81.5 \%)$ \\
Race/ethnicity & Black/African-American & $74(8.2 \%)$ \\
& White & $528(58.6 \%)$ \\
& Hispanic/Latino & $145(16.1 \%)$ \\
& Asian & $41(4.5 \%)$ \\
Family history of type 2 diabetes & Other & $115(12.6 \%)$ \\
& No & $462(51.2 \%)$ \\
Age & Yes & $441(48.8 \%)$ \\
Body mass index & Mean & SD \\
& 21 & 5
\end{tabular}


TABLE 2 | Multiple linear regression analyses showing association between family history of type 2 diabetes (T2D) and exercise and vegetables consumption behavior's among adolescents with a family history of T2D $(n=905)$.

\begin{tabular}{|c|c|c|c|c|c|c|c|c|}
\hline \multirow[b]{2}{*}{ Variable } & \multicolumn{4}{|c|}{ Exercise } & \multicolumn{4}{|c|}{ Vegetable consumption } \\
\hline & $B$ & SE & $\beta$ & $p$ & $B$ & SE & $\beta$ & $p$ \\
\hline Gender & -37.972 & 51.595 & -0.025 & 0.462 & 0.009 & 0.112 & 0.003 & 0.934 \\
\hline Age & 16.616 & 14.751 & 0.039 & 0.260 & 0.099 & 0.032 & 0.106 & 0.002 \\
\hline Hispanic_Latino & 57.255 & 56.490 & 0.042 & 0.311 & -0.079 & 0.123 & -0.027 & 0.520 \\
\hline Black_African_American & 20.918 & 83.437 & 0.011 & 0.802 & -0.332 & 0.181 & -0.076 & 0.067 \\
\hline White & 35.949 & 57.870 & 0.029 & 0.535 & 0.215 & 0.126 & 0.078 & 0.087 \\
\hline Body mass index & -7.378 & 3.663 & -0.069 & 0.044 & -0.009 & 0.008 & -0.039 & 0.245 \\
\hline \multirow[t]{3}{*}{ Family history binary } & -4.811 & 39.322 & -0.004 & 0.903 & 0.135 & 0.085 & 0.053 & 0.115 \\
\hline & $R$ & 0.09 & & & $R$ & 0.20 & & \\
\hline & $R^{2}$ & 0.01 & & & $R^{2}$ & 0.03 & & \\
\hline
\end{tabular}

second degree relative diagnosed with T2D $(76.4 \% ; n=337)$. Number of relatives with T2D ranged from 1 to 9 (mean score $=2.0 ; \mathrm{SD}=1.3)$. Mean number of cups of vegetables eaten in a week was $2.23(\mathrm{SD}=1.3)$, and average number of minutes PA per week was $75.7(\mathrm{SD}=113.5)$. Mean $\mathrm{BMI}$ was 25.3 $(\mathrm{SD}=5.8)$ (see Table 3$)$.

Increased number of relatives with $\mathrm{T} 2 \mathrm{D}$ was significantly associated with PA $(B=27.4, \beta=0.11, p=0.037)$ and with vegetable consumption ( $B=0.129, \beta=0.131, p=0.007)$ after controlling for demographic variables (see Table 4). Having a closer genetic relationship with relatives with $\mathrm{T} 2 \mathrm{D}$ was significantly associated with PA ( $B=83.4, \beta=0.096, p=0.023)$; and with vegetable consumption $(B=0.362, \beta=0.107, p=0.023)$ after controlling for demographic variables (see Table 5). Having a relative with severe T2D was significantly associated with $\mathrm{PA}(B=73.5$, $\beta=0.106, p=0.002)$, and with vegetable consumption $(B=0.501$, $\beta=0.157, p=0.002$ ) after controlling for demographic variables (see Table 6).

\section{DISCUSSION}

Results suggest that there is an association between practicing health-protective behaviors and familial risk profile. In particular, having (a) relatives with severe T2D, (b) greater number of relatives with $\mathrm{T} 2 \mathrm{D}$, and (c) a close genetic relationship with a relative with T2D is associated with increased PA levels and consumption of healthy food options. It is noteworthy that these associations would not have been detectable unless a more nuanced assessment of T2D risk was employed. In other words, a dichotomous family history measure, which simply indicates whether or not a family member has been diagnosed with T2D, did not identify a statistically significant relationship between T2D family history and health behaviors. Consequently, we recommend practitioners and researchers cease using simple, dichotomous measures of family history, which ignore important factors, such as familial risk profiles and "closeness" of relatives. If dichotomous measures are employed, it is imperative that follow-up assessment examine contextual factors (i.e., risk, "closeness") for those indicated presence of a family T2D history. While the results herein document associations between T2D risk and PA and dietary behaviors, it is beyond the scope of this investigation to outline the underlying mechanisms of these associations. Previous research, however,
TABLE 3 | Demographic characteristics of college students with a family history of type 2 diabetes (T2D) $(n=441)$.

\begin{tabular}{llc}
\hline Sex & Male & $64(14.5 \%)$ \\
& Female & $375(85.5 \%)$ \\
Race/ethnicity & Black/African-American & $50(11.3 \%)$ \\
& White & $265(60 \%)$ \\
& Hispanic & $126(28.6 \%)$ \\
Genetic closeness to relative with T2D & First and second degree & $337(76.4 \%)$ \\
& Third degree & $104(23.6 \%)$ \\
Severity of relatives T2D & Yes & $207(47.2 \%)$ \\
& No & $231(52.7 \%)$ \\
Number of relatives with T2D & Mean & SD \\
Age & 2.0 & 1.3 \\
Body mass index & 20 & 1.4 \\
Physical activity & 25.3 & 5.8 \\
Vegetable consumption & 75.7 & 113.5 \\
\hline
\end{tabular}

contend that representations of illness can create feelings of vulnerability, which can in turn motivate an individual to action (46). For example, if an individual observes a close relative constantly battling complications associated with T2D (e.g., emergency department visits, blindness, limb amputation), their specific illness representation will be quite different than a person who has never observed, firsthand, the impact of T2D on a family member. These unique individual experiences, in turn, likely influence an individual's perceived risk of T2D and feelings of vulnerability to the disease. Experiencing T2D in the family, particularly when the illness has become severe or when several relatives are diagnosed with T2D, can heighten emotions. Emotions, according to Ferrer et al. (47), are defined as "a relatively brief affective reaction to a specific person, situation, or sensory stimuli" (47). Emotional feelings have been found to strongly influence health decision-making and have demonstrated very strong influences on engaging in health behaviors (47-50). Moreover, similarities and/or dissimilarities between an individual and their respective family member living with T2D (e.g., biological sex, age, personality type, lifestyle behaviors, physical stature, and body features) may also be influential factors on perceived risk and feelings of vulnerability to T2D. Future examinations should investigate the impact of these factors, and whether they mediate the relationship between T2D and engagement in protective behaviors, such as PA and dietary behaviors. 
TABLE 4 | Multiple linear regression analyses showing association between number of relatives with type 2 diabetes (T2D) and exercise and vegetables consumption behavior's among adolescents with a family history of T2D $(n=441)$.

\begin{tabular}{|c|c|c|c|c|c|c|c|c|}
\hline \multirow[b]{2}{*}{ Variable } & \multicolumn{4}{|c|}{ Exercise } & \multicolumn{4}{|c|}{ Vegetable consumption } \\
\hline & $B$ & SE & $\boldsymbol{\beta}$ & $p$ & $B$ & SE & $\beta$ & $p$ \\
\hline Gender & -42.682 & 47.494 & -0.043 & 0.369 & -0.292 & 0.174 & -0.079 & 0.094 \\
\hline Age & 19.233 & 12.497 & 0.076 & 0.125 & 0.116 & 0.046 & 0.121 & 0.012 \\
\hline Hispanic_Latino & 26.518 & 47.571 & 0.035 & 0.578 & -0.265 & 0.174 & -0.092 & 0.129 \\
\hline Black_African_American & -65.525 & 67.722 & -0.059 & 0.334 & -0.443 & 0.248 & -0.106 & 0.075 \\
\hline White & -19.457 & 48.538 & -0.027 & 0.689 & 0.268 & 0.178 & 0.099 & 0.132 \\
\hline Body mass index & -5.603 & 2.900 & -0.094 & 0.054 & -0.021 & 0.011 & -0.094 & 0.049 \\
\hline \multirow[t]{3}{*}{ Number of relatives with T2D } & 27.427 & 13.094 & 0.105 & 0.037 & 0.129 & 0.048 & 0.131 & 0.007 \\
\hline & $R$ & 0.18 & & & $R$ & 0.29 & & \\
\hline & $R^{2}$ & 0.03 & & & $R^{2}$ & 0.09 & & \\
\hline
\end{tabular}

TABLE 5 | Multiple linear regression analyses showing association between genetic closeness with relatives with type 2 diabetes (T2D) and Exercise and vegetables consumption behavior's among adolescents with a family history of T2D $(n=441)$.

\begin{tabular}{|c|c|c|c|c|c|c|c|c|}
\hline \multirow[b]{2}{*}{ Variable } & \multicolumn{4}{|c|}{ Exercise } & \multicolumn{4}{|c|}{ Vegetable consumption } \\
\hline & $B$ & SE & $\boldsymbol{\beta}$ & $p$ & $B$ & SE & $\boldsymbol{\beta}$ & $p$ \\
\hline Gender & -80.038 & 50.291 & -0.076 & 0.112 & -0.215 & 0.191 & -0.053 & 0.259 \\
\hline Age & 5.579 & 13.222 & 0.021 & 0.673 & 0.097 & 0.050 & 0.093 & 0.054 \\
\hline Hispanic_Latino & 93.421 & 49.949 & 0.115 & 0.062 & -0.199 & 0.189 & -0.063 & 0.294 \\
\hline Black_African_American & -41.729 & 71.418 & -0.035 & 0.559 & -0.351 & 0.271 & -0.077 & 0.196 \\
\hline White & 34.690 & 51.199 & 0.046 & 0.498 & 0.326 & 0.194 & 0.110 & 0.094 \\
\hline Body mass index & -4.234 & 3.076 & -0.067 & 0.169 & -0.025 & 0.012 & -0.104 & 0.029 \\
\hline \multirow[t]{3}{*}{ Genetic closeness to relative with T2D } & 83.440 & 41.949 & 0.096 & 0.047 & 0.362 & 0.159 & 0.107 & 0.023 \\
\hline & $R$ & 0.19 & & & $R$ & 0.29 & & \\
\hline & $R^{2}$ & 0.04 & & & $R^{2}$ & 0.10 & & \\
\hline
\end{tabular}

TABLE 6 | Multiple linear regression analyses showing association between severity of relatives type 2 diabetes (T2D) and exercise and vegetables consumption behavior's among adolescents with a family history of T2D $(n=441)$.

\begin{tabular}{|c|c|c|c|c|c|c|c|c|}
\hline \multirow[b]{2}{*}{ Variable } & \multicolumn{4}{|c|}{ Exercise } & \multicolumn{4}{|c|}{ Vegetable consumption } \\
\hline & $B$ & SE & $\boldsymbol{\beta}$ & $p$ & $B$ & SE & $\boldsymbol{\beta}$ & $p$ \\
\hline Gender & -45.999 & 47.249 & -0.047 & 0.331 & -0.483 & 0.212 & -0.107 & 0.91 \\
\hline Age & 19.775 & 12.445 & 0.078 & 0.113 & 0.038 & 0.056 & 0.033 & 0.023 \\
\hline Hispanic_Latino & 31.698 & 48.198 & 0.041 & 0.511 & 0.345 & 0.216 & 0.098 & 0.493 \\
\hline Black_African_American & -73.787 & 68.168 & -0.066 & 0.280 & -0.101 & 0.305 & -0.020 & 0.111 \\
\hline White & -27.977 & 48.685 & -0.039 & 0.566 & -0.123 & 0.218 & -0.037 & 0.741 \\
\hline Body mass index & -5.681 & 2.870 & -0.096 & 0.048 & 0.040 & 0.013 & 0.146 & 0.574 \\
\hline \multirow[t]{3}{*}{ Severity of relatives T2D } & 73.550 & 33.225 & 0.106 & 0.027 & 0.501 & 0.149 & 0.157 & 0.002 \\
\hline & $R$ & 0.20 & & & $R$ & 0.30 & & \\
\hline & $R^{2}$ & 0.39 & & & $R^{2}$ & 0.89 & & \\
\hline
\end{tabular}

Each of the individual components of the familial risk profile (i.e., number of family members with T2D, degree of relationship to relative with T2D, and severity of relative's T2D) was an indicator of risk for T2D and demonstrated a statistically significant relationship with preventive health behaviors. It is possible that this relationship is because family members encourage healthy behaviors among the youth and adolescents in the family to protect them from developing T2D, particularly when the family is burdened with disability and financial stress. Although friends are the most influential on adolescent PA behaviors $(29,30)$, it is likely the severe complications that may accompany a family members' T2D may, in fact, motivate other family members without T2D to modify their attitudes, beliefs, and knowledge about T2D, thus encourage health-protective behaviors. Future investigations should seek to explore the relationships among the aforementioned constellation of factors.

\section{Implications and Limitations}

Despite the novel nature of this study, there are several limitations, which need to be noted. First, the data are cross-sectional, which limits inferring causality. Second, it is possible that cases 
of T2D are still undiagnosed; thus, participants may have a family history of T2D but were unaware (51). Additionally, all data for this study were self-report. Women were also overrepresented in our sample, which may have biased our results. The $R$-squared values in the results are low; this could be because some confounding variables were not included in the analyses. For example, the amount of time an individual has known about their family member's T2D may influence when participation in T2D-related behaviors begin. Suppose most of our respondents knew about their family members T2D for only $1-3$ weeks before participating in this study, their responses may have influenced the outcomes and strength of the $R$-squared values. Finally, the survey questions examining PA specifically excluded walking, which may have resulted in an underestimate of PA behaviors.

Several notable implications stem from this study. Although it has become increasingly popular to collect information of T2D family history, most of the information collected is in a binary form (i.e., "do you have a family member living with T2D?" Yes or No). As the results herein highlight, more nuanced family history measures represent better measurement tools. Thus, collecting information on various familial risk profiles such as severity, type, and number of relatives with $\mathrm{T} 2 \mathrm{D}$ can provide greater insights into an individual's level of risk, particularly among overweight/obese populations. Stratifying familial risk information can also provide avenues to systematically organize screening procedures. Early screening among those ranking high in the strata is essential because the time lag between the onset of $\mathrm{T} 2 \mathrm{D}$ and diagnosis is approximately 7 years (52). These high-risk family members can be easily identified based on their familial

\section{REFERENCES}

1. de Miguel-Yanes JM, Shrader P, Pencina MJ, Fox CS, Manning AK, Grant RW, et al. Genetic risk reclassification for type 2 diabetes by age below or above 50 years using 40 type 2 diabetes risk single nucleotide polymorphisms. Diabetes Care (2011) 34(1):121-5. doi:10.2337/dc10-1265

2. Fisher EB, Walker EA, Bostrom A, Fischhoff B, Haire-Joshu D, Johnson SB. Behavioral science research in the prevention of diabetes: status and opportunities. Diabetes Care (2002) 25(3):599-606. doi:10.2337/diacare. 25.3.599

3. Bloomgarden ZT. Type 2 diabetes in the young: the evolving epidemic. Diabetes Care (2004) 27(4):998-1010. doi:10.2337/diacare.27.4.998

4. Dabelea D, Mayer-Davis E, Talton J, Hamman R, Bell R, Dolan L. Is prevalence of type 2 diabetes increasing in youth? The SEARCH for diabetes in youth study. Diabetes (2012) 61(Suppl 1):A61.

5. Gómez-Ambrosi J, Silva C, Galofré JC, Escalada J, Santos S, Gil MJ, et al. Body adiposity and type 2 diabetes: increased risk with a high body fat percentage even having a normal BMI. Obesity (2011) 19(7):1439-44. doi:10.1038/ oby.2011.36

6. Hu FB, Sigal RJ, Rich-Edwards JW, Colditz GA, Solomon CG, Willett WC, et al. Walking compared with vigorous physical activity and risk of type 2 diabetes in women: a prospective study. J Am Med Assoc (1999) 282 (15):1433-9. doi:10.1001/jama.282.15.1433

7. James SA, Jamjoum L, Raghunathan TE, Strogatz DS, Furth ED, Khazanie PG. Physical activity and NIDDM in African-Americans. The Pitt County study. Diabetes Care (1998) 21(4):555-62. doi:10.2337/diacare.21.4.555

8. Joseph J, Svartberg J, Njolstad I, Schirmer H. Incidence of and risk factors for type-2 diabetes in a general population: the Tromso study. Scand J Public Health (2010) 38(7):768-75. doi:10.1177/1403494810380299

9. Weinstein AR, Sesso HD, Lee IM, Cook NR, Manson JE, Buring JE, et al. Relationship of physical activity vs body mass index with type 2 diabetes in women. JAm Med Assoc (2004) 292(10):1188-94. doi:10.1001/jama.292. 10.1188 risk profile for opportunities for both primary and early secondary prevention as a significant number of people diagnosed with T2D already have complications at the time of diagnosis (52-54). Similarly, the period when family members experience a relative's T2D severity may create an opportunity to educate them about the important relationships of health-protective behaviors, T2D, and overall health status to protect them from developing T2D. We provide insight into possible mechanisms to improve the health-related behavior of adolescents with a family history of T2D (particularly those with several family members with T2D, those who have parents and siblings living with T2D, and those who have a relative with severe T2D).

\section{ETHICS STATEMENT}

All study procedures were vetted and permitted by the Institutional Review Boards of Texas A\&M University, Prairie View A\&M University, and University of the Incarnate Word. Since it was an online and completely anonymous survey, participants were given informed consent to read via email solicitations sent out, all participants were advised that clicking on the survey link indicated consent.

\section{AUTHOR CONTRIBUTIONS}

AA came up with the idea for the paper, ran all the analyses, and drafted the methods and results. WJ drafted the introduction. RM drafted the discussion. $\mathrm{AB}$ contributed throughout the paper and edited the paper.

10. Jeon CY, Lokken RP, Hu FB, van Dam RM. Physical activity of moderate intensity and risk of type 2 diabetes: a systematic review. Diabetes Care (2007) 30(3):744-52. doi: $10.2337 / \mathrm{dc} 06-1842$

11. Owens CS. Diabetes and obesity risks in African American young adult freshmen attending a Historically Black College/University. J Health Care Poor Underserved (2008) 19(4):1096-118. doi:10.1353/hpu.0.0078

12. Harding A, Wareham NJ, Bingham SA, Khaw K, Luben R, Welch A, et al. Plasma vitamin $\mathrm{C}$ level, fruit and vegetable consumption, and the risk of new-onset type 2 diabetes mellitus: the European prospective investigation of cancer - Norfolk prospective study. Arch Intern Med (2008) 168(14):1493-9. doi:10.1001/archinte.168.14.1493

13. Liu S, Serdula M, Janket SJ, Cook NR, Sesso HD, Willett WC, et al. A prospective study of fruit and vegetable intake and the risk of type 2 diabetes in women. Diabetes Care (2004) 27(12):2993-6. doi:10.2337/ diacare.27.12.2993

14. Sargeant L, Khaw K, Bingham S, Day N, Luben R, Oakes S, et al. Original communications-fruit and vegetable intake and population glycosylated haemoglobin levels: the EPIC-Norfolk study. Eur JClin Nutr (2001) 55(5):342-8. doi:10.1038/sj.ejcn.1601162

15. Bazzano LA, Li TY, Joshipura KJ, Hu FB. Intake of fruit, vegetables, and fruit juices and risk of diabetes in women. Diabetes Care (2008) 31(7):1311-7. doi: $10.2337 / \mathrm{dc} 08-0080$

16. Ford ES, Mokdad AH. Fruit and vegetable consumption and diabetes mellitus incidence among US adults. Prev Med (2001) 32(1):33-9. doi:10.1006/ pmed.2000.0772

17. Claassen L, Henneman L, Janssens AC, Wijdenes-Pijl M, Qureshi N, Walter FM, et al. Using family history information to promote healthy lifestyles and prevent diseases; a discussion of the evidence. BMC Public Health (2010) 10:248. doi:10.1186/1471-2458-10-248

18. Valdez R, Yoon PW, Qureshi N, Green RF, Khoury MJ. Family history in public health practice: a genomic tool for disease prevention and health promotion. Annu Rev Public Health (2010) 31:69-87. doi:10.1146/annurev. publhealth.012809.103621 
19. Brunetti A, Chiefari E, Foti D. Recent advances in the molecular genetics of type 2 diabetes mellitus. World J Diabetes (2014) 5(2):128.

20. Nicklas TA, Baranowski T, Baranowski JC, Cullen K, Rittenberry L, Olvera N. Family and child-care provider influences on preschool children's fruit, juice, and vegetable consumption. Nutr Rev (2001) 59(7):224-35. doi:10.1111/j.1753-4887.2001.tb07014.x

21. Scaglioni S, Salvioni M, Galimberti C. Influence of parental attitudes in the development of children eating behaviour. Br J Nutr (2008) 99(S1):S22-5. doi:10.1017/S0007114508892471

22. Trost SG, Owen N, Bauman AE, Sallis JF, Brown W. Correlates of adults' participation in physical activity: review and update. Med Sci Sports Exerc (2002) 34(12):1996-2001. doi:10.1249/01.MSS.0000038974.76900.92

23. Pijl M, Timmermans DR, Claassen L, Janssens AC, Nijpels G, Dekker JM, et al. Impact of communicating familial risk of diabetes on illness perceptions and self-reported behavioral outcomes: a randomized controlled trial. Diabetes Care (2009) 32(4):597-9. doi:10.2337/dc08-1049

24. Rautio N, Jokelainen J, Oksa H, Saaristo T, Peltonen M, Puolijoki H, et al. Family history of diabetes and effectiveness of lifestyle counselling on the cardio-metabolic risk profile in individuals at high risk of type 2 diabetes: 1-year follow-up of the FIN-D2D project. Diabet Med (2012) 29(2):207-11. doi:10.1111/j.1464-5491.2011.03388.x

25. Wijdenes M, Henneman L, Qureshi N, Kostense PJ, Cornel MC, Timmermans DR. Using web-based familial risk information for diabetes prevention: a randomized controlled trial. BMC Public Health (2013) 13(1):1. doi:10.1186/1471-2458-13-485

26. Wing RR, Venditti E, Jakicic JM, Polley BA, Lang W. Lifestyle intervention in overweight individuals with a family history of diabetes. Diabetes Care (1998) 21(3):350-9. doi:10.2337/diacare.21.3.350

27. Baptiste-Roberts K, Gary TL, Beckles GL, Gregg EW, Owens M, Porterfield D, et al. Family history of diabetes, awareness of risk factors, and health behaviors among African Americans. Am J Public Health (2007) 97(5):907-12. doi:10.2105/AJPH.2005.077032

28. Amuta AO, Barry AE. Type 2 diabetes family history and engagement in protective nutrition behaviors: a cross-sectional study of college students. Am J Health Stud (2015) 30(3):135-45.

29. Amuta AO, Crosslin K, Goodman J, Barry AE. Impact of type 2 diabetes threat appraisal on physical activity and nutrition behaviors among overweight and obese college students. Am J Health Behav (2016) 40(4):396-404. doi:10.5993/AJHB.40.4.1

30. Amuta AO, Jacobs W, Barry AE. An examination of family, healthcare professionals, and peer advice on physical activity behaviors among adolescents at high risk for type 2 diabetes. Health Commun (2016) 32(7):857-63. doi:10.1080/10410236.2016.1177907

31. Mongiello LL, Freudenberg N, Jones H, Spark A. Many college students underestimate diabetes risk. J Allied Health (2016) 45(2):81-6.

32. Amuta AO, Barry AE, McKyer J, Lisako E. Risk perceptions for developing type 2 diabetes among overweight and obese adolescents with and without a family history of type 2 diabetes. Am J Health Behav (2015) 39(6):786-93. doi:10.5993/AJHB.39.6.6

33. Centers for Disease Control and Prevention. Body Mass Index (BMI). (2015). Available from: https://www.cdc.gov/healthyweight/assessing/bmi/

34. Dorman JS, Valdez R, Liu T, Wang C, Rubinstein WS, O'Neill SM, et al. Health beliefs among individuals at increased familial risk for type 2 diabetes: implications for prevention. Diabetes Res Clin Pract (2012) 96(2):156-62. doi:10.1016/j.diabres.2011.12.017

35. Forsyth LH, Goetsch VL. Perceived threat of illness and health protective behaviors in offspring of adults with non-insulin-dependent diabetes mellitus. Behav Med (1997) 23(3):112-21. doi:10.1080/08964289709596367

36. Hariri S, Yoon PW, Qureshi N, Valdez R, Scheuner MT, Khoury MJ. Family history of type 2 diabetes: a population-based screening tool for prevention? Genet Med (2006) 8(2):102-8. doi:10.1097/01.gim.0000200949. 52795.df

37. Harrison TA, Hindorff LA, Kim H, Wines RC, Bowen DJ, McGrath BB, et al. Family history of diabetes as a potential public health tool. Am J Prev Med (2003) 24(2):152-9. doi:10.1016/S0749-3797(02)00588-3

38. Nelson D, Kreps G, Hesse B, Croyle R, Willis G, Arora N, et al. The health information national trends survey (HINTS): development, design, and dissemination. J Health Commun (2004) 9(5):443-60. doi:10.1080/10810730490504233
39. Adriaanse MC, Twisk JW, Dekker JM, Spijkerman AM, Nijpels G, Heine RJ, et al. Perceptions of risk in adults with a low or high risk profile of developing type 2 diabetes; a cross-sectional population-based study. Patient Educ Couns (2008) 73(2):307-12. doi:10.1016/j.pec.2008.06.009

40. Adriaanse M, Snoek F, Dekker J, Spijkerman A, Nijpels G, Van der Ploeg H, et al. Perceived risk for type 2 diabetes in participants in a stepwise populationscreening programme. Diabet Med (2003) 20(3):210-5. doi:10.1046/j.14645491.2003.00901.x

41. Bjerggaard M, Philipsen A, Jørgensen ME, Charles M, Witte DR, Sandbaek A, et al. Association of self-perceived body image with body mass index and type 2 diabetes - the ADDITION-PRO study. Prev Med (2015) 75:64-9. doi:10.1016/j.ypmed.2015.03.018

42. Broadbent E, Donkin L, Stroh JC. Illness and treatment perceptions are associated with adherence to medications, diet, and exercise in diabetic patients. Diabetes Care (2011) 34(2):338-40. doi:10.2337/dc10-1779

43. Fischetti N. Correlates among perceived risk for type 2 diabetes mellitus, physical activity, and dietary intake in adolescents. Pediatr Nurs (2015) 41(3):126.

44. Mongiello LL, Freudenberg N, Jones H. Diabetes risk factor knowledge varies among multiracial college students. J Immigr Minor Health (2015) 18(5):971-8. doi:10.1007/s10903-015-0250-9

45. Piccinino L, Griffey S, Gallivan J, Lotenberg LD, Tuncer D. Recent trends in diabetes knowledge, perceptions, and behaviors: implications for national diabetes education. Health Educ Behav (2015) 42(5):687-96. doi:10.1177| 1090198115577373

46. Leventhal H, Kelly K, Leventhal EA. Population risk, actual risk, perceived risk, and cancer control: a discussion. J Natl Cancer Inst Monogr (1999) 25:81-5. doi:10.1093/oxfordjournals.jncimonographs.a024214

47. Ferrer R, Klein W, Lerner J, Reyna V, Keltner D. Emotions and health decision making: extending the appraisal tendency framework to improve health and health care. Behav Econ Public Health (2014). doi:10.1093/med/ 9780199398331.003.004

48. Chapman GB, Coups EJ. Emotions and preventive health behavior: worry, regret, and influenza vaccination. Health Psychol (2006) 25(1):82. doi:10.1037/0278-6133.25.1.82

49. DeSteno D, Gross JJ, Kubzansky L. Affective science and health: the importance of emotion and emotion regulation. Health Psychol (2013) 32(5):474. doi:10.1037/a0030259

50. Lawton R, Conner M, McEachan R. Desire or reason: predicting health behaviors from affective and cognitive attitudes. Health Psychol (2009) 28(1):56. doi:10.1037/a0013424

51. American Diabetes Association. Statistics about Diabetes, Overall Numbers, Diabetes and Prediabetes. (2015). Available from: http://www.diabetes.org/ diabetes-basics/statistics/?referrer=https://www.google.com/

52. Harris MI, Klein R, Welborn TA, Knuiman MW. Onset of NIDDM occurs at least 4-7 yr before clinical diagnosis. Diabetes Care (1992) 15(7):815-9. doi:10.2337/diacare.15.7.815

53. Kohner EM, Aldington SJ, Stratton IM, Manley SE, Holman RR, Matthews DR, et al. United Kingdom prospective diabetes study, 30: diabetic retinopathy at diagnosis of non-insulin-dependent diabetes mellitus and associated risk factors. Arch Ophthalmol (1998) 116(3):297-303. doi:10.1001/ archopht.116.3.297

54. Spijkerman AM, Dekker JM, Nijpels G, Adriaanse MC, Kostense PJ, Ruwaard D, et al. Microvascular complications at time of diagnosis of type 2 diabetes are similar among diabetic patients detected by targeted screening and patients newly diagnosed in general practice: the Hoorn screening study. Diabetes Care (2003) 26(9):2604-8. doi:10.2337/diacare.26.9.2604

Conflict of Interest Statement: The authors declare that the research was conducted in the absence of any commercial or financial relationships that could be construed as a potential conflict of interest.

Copyright (c) 2017 Amuta, Mkuu, Jacobs and Barry. This is an open-access article distributed under the terms of the Creative Commons Attribution License (CC BY). The use, distribution or reproduction in other forums is permitted, provided the original author(s) or licensor are credited and that the original publication in this journal is cited, in accordance with accepted academic practice. No use, distribution or reproduction is permitted which does not comply with these terms. 